\title{
KAJIAN SOSIAL LINGKUNGAN PERKEBUNAN KELAPA SAWIT BERKELANJUTAN BERDASARKAN ISPO DI PTPN VIII TAMBAKSARI SUBANG JAWA BARAT
}

\author{
Prisman Andri Lesmana Sihombing ${ }^{1)^{*}}$ dan Ernah ${ }^{1)}$ \\ 1) Departemen Sosial Ekonomi, Fakultas Pertanian, Universitas Padjadjaran \\ Jl. Raya Bandung Sumedang KM.21, Kecamatan Jatinangor, Indonesia \\ 1) andrilesmana276@gmail.com
}

\begin{abstract}
ABSTRAK.
Kelapa sawit adalah komoditas yang paling banyak dibudidayakan di Indonesia, hal ini dikarenakan tingginya permintaan pasar international akan minyak nabati. Fenomena ini menimbulkan dampak negatif pada aspek sosial dan lingkungan. Untuk mengatasi hal tersebut, pemerintah mengeluarkan kebijakan yang dikenal dengan ISPO (Indonesian Sustainable Palm Oil) standard, yaitu prinsip dan kriteria untuk perkebunan kelapa sawit di Indonesia yang dibuat sebagai bentuk perwujudan peraturan perundang - undangan dan dukungan Pemerintah Republik Indonesia untuk mewujudkan perkebunan kelapa sawit yang berkelanjutan dan ramah lingkungan. PTPN VIII Kebun Tambaksari adalah salah satu perusahaan perkebunan kelapa sawit yang telah menerapkan standard ISPO dalam pengelolaan perkebunannya. Penelitian ini bertujuan untuk mengkaji sejauh mana pemenuhan aspek sosial dan lingkungan perkebunan kelapa sawit berdasarkan ISPO di PTPN VIII Tambaksari Subang Jawa Barat. Metode penelitian yang digunakan adalah analisis deskrptif kualitatif. Hasil survey menunjukkan bahwa PTPN VIII Tambaksari telah memenuhi hampir semua indikator aspek sosial dan lingkungan sebagaimana yang tercantum dalam Prinsip ISPO.
\end{abstract}

\section{Kata Kunci: Kelapa Sawit, ISPO, Keberlanjutan, Perkebunan}

\section{ABSTRACT}

Palm oil is the most cultivated commodity in Indonesia, this is due to the high international market demand for vegetable oil. This phenomenon has a negative impact on social and environmental aspects. To overcome this, the government issued a policy known as the Indonesian Sustainable Palm Oil (ISPO) standard, namely the principles and criteria for oil palm plantations in Indonesia which were made as a manifestation of legislation and the support of the Government of the Republic of Indonesia to realize oil palm plantations that sustainable and environmentally friendly. PTPN VIII Tambaksari Gardens is one of the oil palm plantation companies that has implemented the ISPO standard in managing their plantations. This study aims to examine the extent of fulfillment of the social and environmental aspects of oil palm plantations based on ISPO at Tambaksari Subang VIII West Java. The research method used is qualitative descriptive analysis. The survey results show that PTPN VIII Tambaksari has fulfilled almost all indicators of social and environmental aspects as stated in the ISPO Principles.

Keywords: Palm Oil, ISPO, Sustainability, Estate 


\section{PENDAHULUAN}

Kelapa Sawit (Elaeis guineensis, Jacq) pertama kali didatangkan ke Indonesia pada tahun 1848 oleh pemerintah Hindia Belanda. Kemudian pada tahun 1870 ditanam di Kebun Raya Bogor dan sisanya benihnya ditanam di Deli, Sumatera Utara sebagai tanaman hias.

Tepat pada pertengahan abad ke-19 terjadi Revolusi Industri yang berdampak meningkatnya permintaan akan minyak mentah dan minyak nabati, selanjutnya muncul ide oleh Pemerintah Hindia Belanda untuk membuat perkebunan kelapa sawit melihat peluang tingginya permintaan minyak nabati. Kelapa sawit adalah salah satu tanaman yang paling banyak ditanam di Indonesia menjadikan Indonesia negara dengan luasan perkebunan kelapa sawit terbesar di dunia sekitar 6,074,926 ha tahun 2006. Tercatat 2.636 .425 ha $(43.40 \%)$ perkebunan milik rakyat, 2.741.802 ha $(45.13 \%)$ perkebunan milik swasta, 696.699 ha $(11.47 \%)$ perkebunan milik negara (Hakim, Memet. 2013).

Tabel 1.Perkembangan Areal Perkebunan Kelapa Sawit di Indonesia

\begin{tabular}{|c|c|}
\hline Tahun & Total (Ha) \\
\hline 2006 & 6.594 .914 \\
\hline 2007 & 6.766 .836 \\
\hline 2008 & 7.363 .847 \\
\hline 2009 & 7.508 .023 \\
\hline 2010 & 7.824 .623 \\
\hline 2011 & 7.900 .000 \\
\hline 2012 & 8.200 .000 \\
\hline 2013 & 8.500 .000 \\
\hline
\end{tabular}

Sumber : Hakim, Memet (2013)

Di Pulau Jawa hanya ada dua Provinsi yang memiliki areal perkebunan kelapa sawit yaitu Provinsi Banten dan Provinsi Jawa Barat. Tahun 2015 luas lahan perkebunan kelapa sawit di Jawa Barat sekitar 14.134 ha.

Tabel 2. Luas Areal Perkebunan Kelapa Sawit di Jawa Barat Tahun 2012 - 2015

\begin{tabular}{|c|c|}
\hline Tahun & Total (Ha) \\
\hline 2012 & 10.880 \\
\hline 2013 & 13.610 \\
\hline 2014 & 13.600 \\
\hline 2015 & 14.134 \\
\hline
\end{tabular}

Sumber : Badan Pusat Statistik (2015)

Dijelaskan pada Tabel 2, perkembangan areal kelapa sawit di Jawa Barat periode 2012 - 2015. Peningkatan tertinggi terjadi antara periode 2012 - 2013 sekitar 2.730 ha, namun periode 2013 - 2014 mengalami penurunan sekitar 100 ha. Periode selanjutnya yakni 2014 - 2015 kembali meningkat sekitar 500 ha. Dari total 14.134 ha luas areal perkebunan kelapa sawit tahun 2015, tercatat 261 ha perkebunan milik rakyat, 3.350 ha perkebunan milik swasta, 10.523 ha perkebunan milik negara. Tingginya permintaan CPO (crude palm oil) dan PKO (palm kernel oil) di pasar global adalah salah satu alasan pesatnya perkembangan areal kelapa sawit di Indonesia.

\section{KAJIAN PUSTAKA}

\section{Kelapa Sawit}


Tanaman kelapa sawit (Elaeis

guineensis, Jacq.) berasal dari Nigeria,

Afrika Barat. Namun kebanyakan

pendapat menyatakan bahwa kelapa

sawit berasal dari Brazil, Amerika

Selatan dikarenakan banyak ditemukan

spesies kelapa sawit di hutan Brazil

dibandingkan dengan Afrika. Pada

kenyataannya kelapa sawit tumbuh

lebih subur dibanding daerah asalnya,

seperti Indonesia, Malaysia, Thailand

dan Papua Nugini (Fauzi, Yan.2012).

Kelapa sawit memiliki arti penting

bagi pertumbuhan ekonomi Indonesia

selain mampu menciptakan lapangan

pekerjaan juga sebagai sumber

perolehan devisa negara. Beberapa

produk yang dihasilkan dari

pengembangan minyak sawit antara

lain adalah minyak goreng, mentega,

kue/biscuit, sabun dan kosmetik dan

juga biodiesel.

\section{Sosial}

Menurut Joseph S et al, 1984 interaksi

sosial adalah suatu proses, melalui

tindak balas tiap-tiap kelompok

berturutturut menjadi unsur penggerak

bagi tindak balas kelompok yang lain.

Ia adalah suatu proses timbal balik

dengan mana satu kelompok

dipengaruhi oleh tingkah laku reaktif

pihak lain dan dengan berbuat

demikian ia mempengaruhi tingkah

laku orang lain (Joseph S et al, 1984).

Burhan Bungin (2009) menjelaskan

bahwa ada dua golongan dalam proses

sosial yang merupakan akibat interaksi sosial, yaitu Proses Asosiatif dan

Proses Disosiatif.

\section{Lingkungan}

Lingkungan adalah kombinasi antara kondisi fisik yang mencakup keadaan sumber daya alam seperti tanah, air, energy surya, mineral, serta flora dan fauna yang tumbuh diatas tanah maupun di dalam lautan, dengan kelembagaan yang meliputi ciptaan manusia seperti keputusan bagaimana menggunakan lingkungan fisik tersebut. Di Indonesia lingkungan sering disebut dengan lingkungan hidup (Fauzi, 2012).

\section{ISPO (Indonesia Sustainable Palm Oil)}

Pada tanggal 29 Maret 2011

pemerintah melalui Kementrian

Pertanian mengeluarkan peraturan

Menteri Pertanian No.

19/Permentan/OT.140/3/2011 tentang

Pedoman Perkebunan Kelapa Sawit

Berkelanjutan Indonesia (Indonesia

Sustainable Palm Oil - ISPO) bahwa

setiap perusahaan kelapa sawit di

Indonesia wajib memiliki sertifikat

ISPO yang berlaku selama lima tahun

dan setiap sekali dalam setahun

dilakukan auditor pengawasan

(survailance). Peraturan tersebut

direvisi dengan Peraturan Menteri

PertanianNo.11/Permentan/OT.140/3/2

015(Agustina dkk, 2014; Ernah, 2015;

Fuadah dan Ernah, 2018).

\section{METODE PENELITIAN}

Penelitian dilakukan di PTPN VIII

Tambaksari Subang, Jawa Barat. 
Penentuan lokasi penelitian dilakukan dengan sengaja. Tempat penelitian ini dipilih dengan pertimbangan PTPN VIII Tambaksari adalah perusahaan perkebunan kelapa sawit yang telah menerapkan sistem sertifikasi ISPO dalam menjalankan budidaya kelapa sawit. Penelitian ini dilaksanakan pada bulan Agustus - September 2017. Data primer bersumber dari hasil wawancara dan observasi lapang sedangkan data sekunder berasal dari dokumen perusahaan. Desain yang digunakan dalam penelitian ini adalah desain kualitatif. Desain kualitatif merupakan metode penelitian yang berlandaskan pada filsafat postpositivisme, digunakan untuk meneliti pada kondisi objek yang alamiah (sebagai lawannya adalah eksperimen) dimana peneliti adalah sebagai instrument kunci, pengambilan informan dilakukan secara purposive dimana hasil penelitian kualitatif lebih menekankan pada makna daripada generalisasi (Sugiyono, 2013). Tenik penelitian yang sesuai dengan penelitian ini adalah studi kasus yang berfokus pada kasus dalam suatu kejadian baik mencakup individu, kelompok budaya ataupun potret (gambaran) suatu kehidupan(Creswell,1998). Untuk menjelaskan kajian sosial lingkungan pada studi ini digunakan analisis deskriptif.

\section{HASIL DAN PEMBAHASAN}

\section{Gambaran Umun PTPN VIII Kebun Tambaksari}

Perkebunan Tambaksari adalah salah satu perkebunan BUMN dari 41

Perkebunan yang dikelola oleh PT Perkebunan Nusantara VIII (Persero)

yang berkantor pusat di Jalan

Sindangsirna No. 4 Bandung, Jawa

Barat. Gabungan dari tiga unit kebun milik pemerintah kolonial Belanda yaitu Kebun Bukanagara (1902), Kebun Kasomalang (1906), Kebun Tambakan (1922), Kebun Sarireja dan Kebun Sindangsari. Tahun 1950 dialihkan ke Pamanukan n Tjiasem Lands (PnT Lands) milik Kerajaan Inggris. Tahun 1964 dinasionalisasikan oleh Pemerintah Republik Indonesia menjadi BUMN. Perkebunan Tambaksari beberapa kali pengalihan pengelolaan, mulai dari PPN Dwikora IV (1964 - 1970), PP Subang (1970 1973), PT Perkebunan XXX (19731979), PT Perkebunan XIII (1979 1995), dan PT Perkebunan Nusantara VIII (1996 - sekarang). PTPN VIII Kebun Tambaksari, mengelola tiga Afdeling komoditas Teh, yaitu Afdeling Tambaksari, Afdeling Kasomalang, dan Afdeling Bukanagara. Selanjutnya pada tahun 2002 PTPN VIII Kebun Tambaksari membuka dua afdeling baru yaitu Afdeling Sindangsari dan Afdeling Serangsari dengan komoditas kelapa sawit berupa TBS (tandan buah segar) dan diolah di PKS (pabrik kelapa sawit) Cikasungka. 
Kajian Sosial dan Lingkungan Berdasarkan Kriteria ISPO

\section{Tanggung Jawab Sosial Lingkungan Kemasyarakatan}

Mengacu pada Undang - Undang

Nomor 40 Tahun 2007 dan Prosedur

ISPO (Indonesian Sustainable Palm

Oil) PTPN VIII Tambaksari

melaksanakan Tanggung Jawab Sosial

dan Lingkungan yang berfungsi

memberdayakan masyarakat.

Tanggung Jawab Sosial dan

Lingkungan PTPN VIII Tambaksari

berbentuk CSR (Corporate Social

Responsibility). CSR PTPN VIII

dibuat untuk masyarakat yang tempat tinggalnya berdampingan langsung dengan perkebunan PTPN VIII Tambaksari yaitu Desa Kasomalang, Desa Kumpay, Desa Tambakan (Afdeling Sindangsari) dan Desa Cijengkol (Afdeling Serangsari). CSR PTPN VIII Tambaksari terbagi dalam 6 (enam) jenis kegiatan pemberdayaan masyarakat yaitu: (1) Penyelenggaraan Kegiatan Pendidikan. (2)

Penyelenggaraan Kegiatan Kesehatan.

(3) Penyelenggaraan Kegiatan

Keagamaan. (4) Penyelenggaraan

Kegiatan Pertanian. (5)

Penyelenggaraan Kegiatan Olahraga.

(6) Penyelenggaraan Kegiatan Seni

Budaya. CSR PTPN VIII Tambaksari

juga menerima keluhan dan kebutuhan

masyarakat yang segera ditindaklanjuti

oleh perusahaan, salah satu contoh

kebutuhan masyarakat yang

ditindaklanjuti oleh PTPN VIII
Tambaksari adalah pembangunan sarana sanitasi air bersih di Desa Cijengkol, Kecamatan Serangpanjang. PTPN VIII juga memberdayakan ekonomi masyarakat sekitar kebun dengan memberikan kesempatan kerja kepada masyarakat sekitar kebun untuk menjadi pegawai atau karyawan di PTPN VIII Tambaksari, masyarakat juga diberikan kesempatan bilamana masyarakat ingin mendirikan usaha seperti warung diatas tanah PTPN VIII Tambaksari dengan perjanjian bangunan tidak permanen dan dapat dibongkar jika lahan tersebut ingin digunakan oleh perusahaan.

\section{Pemberdayaan Masyarakat Adat/Penduduk Asli}

Tidak ada program khusus untuk peningkatan kesejahteraan masyarakat hukum adat (penduduk asli), penyebab dari tidak adanya program tersebut dari pihak PTPN VIII Tambaksari dikarenakan masyarakat desa yang bermukim di sekitar lingkungan atau berdampingan langsung dengan kebun PTPN VIII Tambaksari adalah masyarakat dengan penduduk mayoritas dan rata - rata penduduk asli desa tersebut. Oleh sebab itu program pemberdayaan masyarakat yang telah dibuat oleh perusahaan sudah mencakup program pemberdayaan masyarakat hukum adat (penduduk asli).

\section{Pengembangan Usaha Lokal}

Pengembangan usaha lokal adalah salah satu bentuk partisipasi PTPN VIII Tambaksari dalam memajukan roda perekonomian masyarakat sekitar. Masyarakat yang memiliki potensi 
dapat menjalin kerjasama dengan

PTPN VIII Tambaksari.

Kewajiban Terkait Izin Lingkungan

Menindak lanjuti Peraturan

Pemerintah Republik Indonesia Nomor

27 Tahun 2012. PTPN VIII dalam hal

ini telah melakukan dan menerapkan

Izin Lingkungan sesuai dengan

Peraturan Pemerintah Republik

Indonesia Nomor 27 Tahun 2012,

mengacu pada: (1) Surat Izin

Pengambilan Dan Pemanfaatan Air

Tanah (2) Surat Izin Penyimpanan

Sementara Limbah Bahan Berbahaya

dan Beracun (B3) Subang.

Pengolahan Bahan Berbahaya Dan

Beracun (B3)

Peraturan Pemerintah Nomor 18

Tahun 1999 Tentang Pengolahan

Limbah Bahan Berbahaya dan Beracun

(B3), Peraturan Pemerintah Nomor 85

Tahun 1999 Tentang Pengolahan

Limbah Bahan Berbahaya dan Beracun

(B3), Keputusan Kepala BAPEDAL

Nomor 01/BAPEDAL/09/1995

Tentang Tata Cara dan Persyaratan

Teknis Penyimpanan Limbah Bahan

Berbahaya dan Beracun, Peraturan

Menteri Lingkungan Hidup Nomor

14/2013 Tentang Simbol dan Label

Bahan Berbahaya dan Beracun.

Menindak lanjuti peraturan perundang

- undangan tersebut PTPN VIII Kebun

Tambaksari telah membangun tempat

penyimpanan limbah bahan berbahaya

dan beracun (B3) dengan kriteria

sebagai berikut : (a) Memiliki Izin

Penyimpanan Sementara Limbah
Bahan Berbahaya dan Beracun (B3)

dari Badan Lingkungan Hidup

Kabupaten Subang dengan Surat

Nomor : 660.1/132/201, (b) Berlokasi

di area bebas banjir dan berjarak

minimum $300 \mathrm{~m}$ dari aktifitas dan

pemukiman penduduk; (c) Tempat

penyimpanan limbah B3 sejuk dan

memiliki sirkulasi udara; (d) Memiliki

penerangan dari sumber cahaya atau

matahari; (e) Membuat peringatan

berupa simbol dan label di pintu

masuk dan di dalam TPS (tempat

penyimpanan sementara); (f)

Meletakkan limbah dan menyusun

limbah sesuai dengan jenis dan

karateristik limbah tersebut; (g)

Limbah dengan karateristik mudah

terbakar disimpan dalam ruangan

khusus jauh dari sumber api dan tidak

terkena cahaya matahari langsung; (h)

Tersedia alat pelindung diri berupa

sarung tangan dan tersedia tempat

untuk membersihkan tangan bagi

pekerja setelah menyimpan limbah; (i)

Tersedia sarana APAR jika terjadi

kebakaran dan kotak P3K (penolongan

pertama pada kecelakaan); (j)

Kemasan limbah dalam kondisi baik, tidak rusak, bebas karat dan tidak bocor; (k) Tersedia dokumen neraca keluar masuk limbah; (1) Tersedia SDM yang menangani dan mengurus tempat penyimpanan limbah; (m) Tersedia SOP (system operational procedure).

Berikut ini adalah daftar bahan berbahaya dan beracun (B3) yang 
dihasilkan oleh PTPN VIII Kebun

Tambaksari:

Tabel 3. Daftar Bahan Berbahaya dan Beracun (B3)

\begin{tabular}{|c|l|c|c|}
\hline No & $\begin{array}{l}\text { Nama } \\
\text { Barang }\end{array}$ & Jenis & Karateristik \\
\hline 1 & Oli & Cair & $\begin{array}{c}\text { Mudah } \\
\text { Terbakar }\end{array}$ \\
\hline 2 & Accu & Padat & Korosif \\
\hline 3 & $\begin{array}{l}\text { Jeligen } \\
\text { Herbisida }\end{array}$ & Padat & Beracun \\
\hline 4 & $\begin{array}{l}\text { Kaleng } \\
\text { Bekas } \\
\text { Kemasan } \\
\text { Pestisida }\end{array}$ & Padat & Beracun \\
\hline 5 & $\begin{array}{l}\text { Lampu } \\
\text { TL }\end{array}$ & Padat & $\begin{array}{c}\text { Berbahaya } \\
\text { Bagi } \\
\text { Lingkugan }\end{array}$ \\
\hline
\end{tabular}

Sumber: Dokumen PTPN VIII FM-ADS-04.01

Pencegahan Dan Penanggulangan

Kebakaran

PTPN VIII Tambaksari membuat SOP

(system operational procedure) untuk mencegah dan menanggulangi jika terjadi kebakaran. PTPN VII Tambaksari menyediakan alat penanggulangan kebakaran seperti Alat Pemadam Api Ringan (APAR), bak berisi pasir dan karung goni basah untuk memadamkan api yang bersumber dari bahan bakar/kimia, mobil operasional kebun yang berfungsi mengangkut air ke lokasi terjadinya kebakaran, membangun bak penampungan air di sekitar areal kebun untuk mempermudah Tim mengambil air.

Pelestarian Keanekaragaman Hayati (Biodiversity)
Pelestarian keanekaragaman hayati

(biodiversity) adalah upaya

melestarikan keanekaragaman hayati seperti flora dan fauna yang hidup di kebun PTPN VIII Kebun Tambaksari agar tidak diburu, dirusak dan tidak punah. Pelestarian keanekaragaman hayati ini mencakup perlindungan flora dan fauna bertujuan untuk melindungi flora dan fauna yang berada di areal perkebunan kelapa sawit PTPN VIII Kebun Tambaksari atau satwa liar yang bermigrasi ke dalam areal perkebunan beserta seluruh ekositem habitat dari satwa liar tersebut. PTPN VIII Kebun

Tambaksari juga melakukan sosialisasi di Desa dan Sekolah sekitar areal kebun tentang keberadaan flora dan fauna tersebut. Upaya konservasi yang dilakukan oleh PTPN VIII Kebun Tambaksari berupa pembuatan poster "Dilarang Berburu".

\section{Konservasi Terhadap Sumber Air Dan Kualitas Air}

Perkebunan Kelapa Sawit PTPN VIII

Tambaksari dalam kegiatannya memanfaatkan air hujan untuk penyiraman tanaman kelapa sawit, untuk keperluan penunjang kebun dan MCK (mandi, cuci, kakus) karyawan juga masyarakat, PTPN VIII Kebun Tambaksari mengambil dan memanfaatkan air tanah. Pengambilan dan pemanfaatan air tanah telah memiliki izin berdasarkan Surat Keputusan Kepala Dinas Pertambangan Dan Energi Kabupaten 
Subang Nomor: 546.2/173/SIPA-

GSDM/2014. Demi penggunaan air secara efisien, PTPN VIII Kebun Tambaksari membatasi penggunaan air, penggunaan debit air maksimal di kebun PTPN VIII Tambaksari adalah 70 meter $^{3} /$ hari. Guna menjaga air buangan tidak terkontaminasi limbah, PTPN VIII Tambaksari membangun sumur resapan untuk limbah MCK (mandi, cuci, kakus) dan tidak dialirkan ke sungai, untuk air yang penggunaanya mencuci alat bekas menyemprot pestisida dibangun bak penampung air bekas mencuci alat semprot tersebut kemudian air disaring dan dialirkan ke dalam sumur resapan.

\section{Kawasan Lindung}

Tidak adanya kawasan lindung di areal perkebunan kelapa sawit PTPN VIII Tambaksari dikarenakan lahan kebun kelapa sawit berasal dari lahan konversi komoditas kakao dan karet dibuktikan dengan Surat Bupati Subang Nomor : 525/395/Hutbun, Perihal : Konversi Tanaman Kakao dan Karet Perkebunan PTPN VIII Tambaksari Jawa Barat Menjadi Tanaman Kelapa Sawit yang ditetapkan tanggal 22 Juli 2008.

\section{Konservasi Kawasan Dengan Potensi Erosi Tinggi}

Konservasi kawasan dengan potensi erosi tinggi adalah pelestarian atau pencegahan terjadinya longsor yang berakibat merusak lingkungan.

Dikatakan potensi erosi tinggi jika tingkat kelerengan tanah melebihi $>40^{\circ}$. Meninjau hal tersebut PTPN

VIII Tambaksari membuat SOP (system operational procedure) yang menjamin bahwa kawasan dengan potensi erosi tinggi terjaga dengan baik. Upaya yang dilakukan PTPN VIII Tambaksari untuk mencegah terjadinya longsor di daerah dengan potensi erosi tinggi adalah membuat tongkat pengukur (patok), tongkat pengukur (patok) yang dimaksud adalah tongkat berdiameter $5 \mathrm{~cm}$ dan memiliki panjang $150 \mathrm{~cm}$ yang ditanam ke dalam permukaan tanah, dipergunakan untuk mengukur (menduga) besarnya erosi yang terjadi pada suatu areal dan masa tertentu.

\section{Mitigasi Gas Rumah Kaca (GRK)} PTPN VIII Tambaksari dalam kegiatan mitigasi gas rumah kaca menerapkan 2 (dua) program untuk penerapan penangkapan gas metan demi mengurangi emisi GRK. Program tersebut adalah: (1) Program Mitigasi REDD (Reduction Emission of Degradation) adalah program untuk meningkatkan penyerapan Carbon, dengan menanam atau menambah tanaman atau pepohonan yang efektif menyerap karbon melalui proses fotosintesis. (2) Program Mitigasi CDM (Carbon Development Mechanism) adalah program mengurangi dan atau mengganti sumber emisi GRK, dengan bahan atau material baru, peralatan, sarana atau menerapkan metode baru yang diperhitungkan lebih efektif 
mengurangi emisi dibandingkan sebelumnya.

\section{KESIMPULAN DAN SARAN}

PTPN VIII Tambaksari telah memenuhi indikator aspek lingkungan dan aspek sosial yang terangkum dalam Prinsip dan Kriteria ISPO (Indonesian Sustainable Palm Oil) tentang sosial dan pengolahan lingkungan secara berkelanjutan. Dalam memaksimalkan pemenuhan aspek sosial dan lingkungan ISPO perlu dilakukan pengawasan dan evaluasi dari PTPN VIII Tambaksari agar dapat terus ditingkatkan sesuai dengan perkembangan kondisi sosial dan lingkungan.

\section{Ucapan Terima Kasih}

Ucapan terima kasih disampaikan kepada Rektor Universitas Padjadjaran atas Hibah Internal Unpad yang telah membiayai penelitian ini dan juga untuk PTPN VIII Tambak Sari Subang Jawa Barat dan semua pihak yang telah membantu dalam penelitian ini.

\section{Referensi}

Agustina, Dewi; Hariyadi dan Saharuddin. 2014. Analisis Lingkungan Sosial Ekonomi Pengelolaan Perkebunan Kelapa Sawit Berkelanjutan Berdasarkan Kriteria Ispo Pt. Tapian Nadenggan. Jurnal Pengelolaan Sumberdaya Alam dan Lingkungan Vol. 4 No. 1.
Badan Pusat Statistik Provinsi Jawa Barat, 2015 (http://bps.go.id) Diakses pada tanggal 1 Juli 2017.

Burhan Bungin. 2009. Sosiologi Komunikasi.: Teori, Paradigma, dan Diskursus Teknologi Komunikasi di Masyarakat. Jakarta : Kencana Prenada Media Group.

Creswell, John W. 1998. "Qualitative Inquiry and Research Design : Choosing Among Five Tradition".(http://file.upi.edu ). Diakses pada tanggal 23 Juli 2017.

Ernah. 2015. Cost-Benefit Analysis Of The Introduction Of The Indonesian Sustainable Palm Oil Standards: A Case Study In Jambi Province, Sumatra, Indonesia.

Fuadah, Deilla Tsamrotul dan Ernah. 2018. Pengelolaan Perkebunan Kelapa Sawit Berdasarkan Prinsip ISPO di PTPN VIII Cikasungka, Jawa Barat. Jurnal Ilmu Pertanian Indonesia (JIPI) Vol. 23 (3): 190-195.

Fauzi, Ahmad.2010. Ekonomi Sumebr Daya alam dan Lingkungan, teori dan aplikasi. Penerbit PT Gramedia Pustaka Umum . Jakarta

Fauzi, Yan 2012. Kelapa Sawit. Penerbit Penebar Swadaya.

Joseph S Roucek, dan Rolland L. Warren. 1984. Pengantar Sosiology.

Hakim, Memet. 2013. Teknis Agronomis Dan Manajemen 
Kelapa Sawit. Bandung:

Penerbit Media Perkebunan.

Sugiyono. 2013 Metodologi Penelitian

Kuantitatif Kualitatif dan

$R \& D$. Bandung: Penerbit PT.

Alfabeta. 